\title{
Optimization of Adrenal Medullary Allograft Conditions for Pain Alleviation
}

\author{
Hong Wang and Jacqueline Sagen \\ Department of Anatomy and Cell Biology, University of Illinois at Chicago \\ 808 S. Wood Street, Chicago, IL 60612, USA
}

\begin{abstract}
SUMMARY
Previous findings in our laboratory have demonstrated that transplants of adrenal medullary tissue into the spinal subarachnoid space can alleviate pain, most likely via sustained local release of pain-reducing neuroactive substances from the transplanted chromaffin cells. The success of this work in animal models has led to preliminary clinical trials with promising results. However, before large-scale clinical studies are undertaken, numerous issues should be resolved, many of which can be readily addressed initially in the laboratory. One of these is the amount of donor adrenal medullary tissue necessary to produce long-term antinociception. Although tissue from two adrenal glands has generally been used, it is unknown whether less would be equally effective, or more could increase analgesic potency. To address this, various amounts of adrenal medullary tissue, ranging from one to ten donor glands, were used. Results showed lowered antinociceptive benefits when only one adrenal medulla was used, but only small and short-lived increases when donor material was increased substantially. In addition, assays of catecholamine and Met-enkephalin release in the host spinal CSF revealed only slight further increases following the transplantation of more than 2-4 glands. These results indicate that a
\end{abstract}

Reprint address:

J. Sagen

Department of Anatomy and Cell Biology

University of Illinois at Chicago

808 S. Wood Street, Chicago, IL 60612, USA small amount of adrenal medullary tissue is necessary and sufficient to produce sustained antinociception, and suggest that higher amounts may result in tolerance development or feedback inhibition. Another important issue is the ability to retain antinociceptive potency if donor tissue is maintained in culture prior to transplantation, since the coordination of donor harvesting and recipient availability is often difficult. To address this, donor adrenal medullary tissue was maintained in explant culture for various periods following dissection. Results indicated that adrenal medullary tissue can be maintained in culture for up to $\mathbf{3 0}$ days prior to transplantation without decrement in antinociceptive potency, and that a period of 721 days results in improved graft viability. Results of this study indicate that some of the critical issues for successful neural transplantation outcomes can be initially addressed in pre-clinical studies.

\section{KEY WORDS}

neural transplants, nociception, analgesia, chromaffin cells, catecholamines, opioid peptides, explant culture

\section{INTRODUCTION}

Chromaffin cells in the adrenal medulla produce and release several neuroactive substances which make them viable candidates as a graft source for pain alleviation. In particular, these cells synthesize and release opioid peptide products from the proenkephalin precursor $/ 2,12,13,23,30 /$, in addition 
to catecholamines. Notably, both opioid and $\alpha$ adrenergic agonists reduce nociception when injected locally into the spinal subarachnoid space. Furthermore, the co-administration of subeffective doses of both types of agents appears to synergistically produce potent analgesia, with limited tolerance development $/ 4,22,29,36 /$. Thus, adrenal medullary transplants may provide an ideal combination of pain-reducing neuroactive agents for the long-term alleviation of pain. Previous studies in our laboratory have demonstrated that the transplantation of adrenal medullary tissue into the spinal subarachnoid space of rats can reduce pain symptoms in acute and chronic pain models $/ 10,18,20 /$. This is most likely due to the co-release of both opioid peptides and catecholamines from the transplanted cells since it can be blocked by either opioid or $\alpha$-adrenergic antagonists $/ 18,20 /$. Furthermore, adrenal medullary transplants result in elevated CSF levels of Met-enkephalin and catecholamines for at least 6 months following transplantation $/ 15,16 /$. The success of these studies has led to limited clinical trials in cancer pain patients with promising findings $/ 19 /$.

Prior to attempting larger-scale clinical trials, several basic issues need to be resolved. Many of these can be addressed, at least initially, in the laboratory. For example, the preparation of adrenal medullary allograft tissue for transplantation in order to optimize pain-reducing capabilities, as well as logistics, is critical to the success of this approach. Previous studies in our laboratory have utilized adrenal medullary tissue from two donor glands. This reliably reduces pain sensitivity and increases CSF levels of pain-reducing neuroactive substances following transplantation into the host spinal subarachnoid space. However, neither the minimum nor optimum amount of donor tissue for pain reduction has been determined. In addition, in previous studies, adrenal medullary tissue has been removed from donors and transplanted immediately into the spinal subarachnoid space of host animals. This procedure may be inconvenient for clinical purposes, since it is often difficult to coordinate harvesting of donor tissue with timing for surgical implantation. One approach to overcoming this difficulty would be to maintain the donor tissue in culture prior to transplantation. Another advantage of maintaining tissue in explant culture is that it may allow for recovery from anoxic trauma following dissection. Thus, the goal of the present studies was to assess optimal procedures to increase the likelihood of successful pain reduction by adrenal medullary allografts. A preliminary account of these results has been presented previously /27/.

\section{MATERIALS AND METHODS}

\section{Animals}

In all of the following studies, male SpragueDawley rats $(250-300 \mathrm{~g})$ were used as both hosts and donors. The rats were obtained from Sasco Laboratories (WI) and housed in the animal care facility at the University of Illinois at Chicago. These procedures followed the guidelines for the care and use of animals established by the Society for Neuroscience and the Animal Care Committee at the University of Illinois at Chicago.

\section{Preparation of transplant tissue}

Donor adrenal medullary tissue was obtained from adult rats and prepared for transplantation as illustrated in Figure 1. The donors were anesthetized with ether and killed by cervical dislocation. Their adrenal glands were rapidly removed aseptically and placed in ice cold Hanks' buffer. Under a dissecting microscope, adrenal cortical tissue was carefully dissected from the medullary tissue. Adrenal medullary tissue was cut into small pieces (0.5-1.0 cu.mm) and either placed in ice-cold Hanks' buffer for transplantation (within $30 \mathrm{~min}$ following dissection; Fig. 1 at A), or placed in tissue culture for various periods of time prior to transplantation (Fig. 1 at B). The latter was done in order to assess the consequences and limitations of maintaining the tissue for various periods prior to transplantation. For tissue culture, the adrenal medullary pieces were washed in Locke's buffer containing kanamycin, penicillin-streptomycin, and fungizone for 10 to 15 minutes, and placed in culture by 


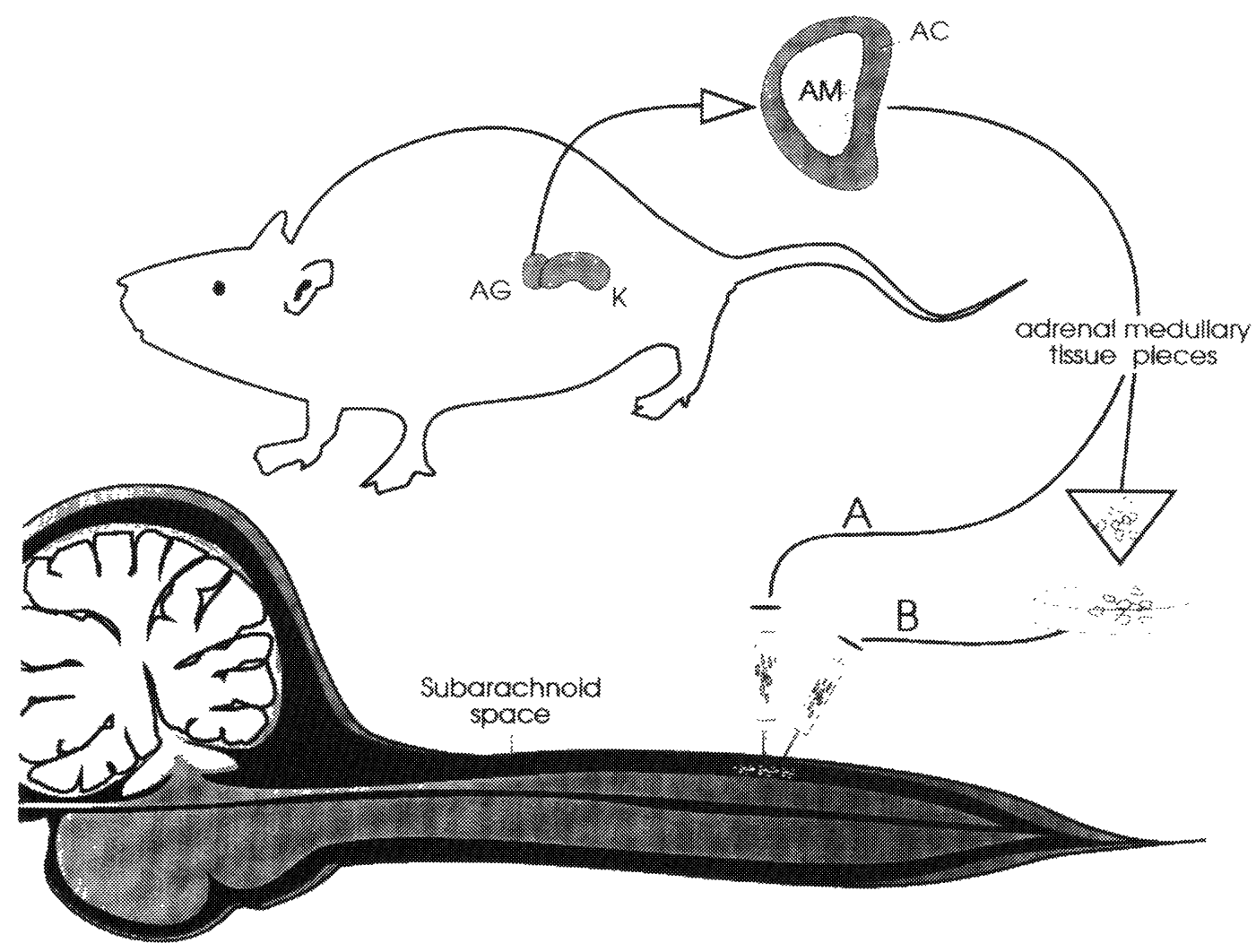

Fig. 1: Diagram of surgical implantation of rat adrenal medullary transplants (A) or adrenal medullary explants (B) into the spinal cord subarachnoid space of rats (see text for details). AG: adrenal gland; K: kidney; AC: adrenal cortex; AM: adrenal medulla.

seeding in small volumes of 1:1 DMEM:F12 medium containing $50 \%$ fetal bovine serum at $37^{\circ} \mathrm{C}$ and $5 \% \mathrm{CO}_{2}$. The low volume and high serum aid in the initial attachment of the pieces to the 24-well culture plates. The explanted adrenal medullae were incubated at $37^{\circ} \mathrm{C}$ and $5 \% \mathrm{CO}_{2}$ for $2-3$ hours before more medium was added gradually over a 2-3 day period until a final concentration of $5 \%$ FBS in $1: 1$ DMEM:F12 was reached. Explants were maintained in tissue culture for $1,3,7,10,14,21$ and 30 days until transplanted. When used for surgery, the explants were washed and transferred in Hanks' buffer until transplanted (within $30 \mathrm{~min}$ ). Striated muscle tissue from the same rat strain was used for control grafting. The preparation of control tissue for either immediate implantation or implantation following culturing was the same as that for the adrenal medullary tissue.
Surgical transplantation in the spinal subarachnoid space of the rat

Tissue for transplantation was introduced into the spinal subarachnoid space of host animals using aseptic surgical techniques (Fig. 1). Animals were anesthetized with pentobarbital $(30 \mathrm{mg} / \mathrm{kg}$, i.p., supplemented as necessary). A laminectomy was performed to expose a 3-4 mm segment of the lumbar enlargement. Under a dissecting microscope, a small slit was made in the dura and arachnoid mater. In order to determine minimum and optimal graft tissue amounts for reduction of pain, tissue ranging from 1-10 adrenal medullae was used (see Experimental Design). In control animals, equal volumes of striated muscle were used. Graft tissues were placed in the subarachnoid space and pushed under the dura and arachnoid away from the slit to 
keep them in place. Following implantation, the musculature was sutured with 3-0 silk, and the skin was closed with wound clips.

\section{Analgesiometric tests}

Acute pain sensitivity in these studies was assessed by use of the tail flick test, the paw pinch test, and the hot plate test. The tail flick test $/ 3 /$ measures a simple reflect to avoid a noxious thermal stimulus. To determine response to the tail flick test, a radiant heat stimulus was focused on the blackened area of the dorsal surface of the rat's tail and the time interval between the onset of the stimulus and the tail flick response was measured at three regions of the tail, the average of which was defined as the 'tail flick latency'. To prevent tissue damage in the absence of a response, the stimulus was terminated at 14 seconds and the tail flick latency assigned a value of 14 .

The paw pinch response is a reflexive response to mechanical pressure, elicited by a commercially available apparatus (Ugo-Basile) that applies pressure at a constant increasing rate of $64 \mathrm{~g} / \mathrm{sec}$. The force was applied to the ventral surface of both hind paws sequentially until the animal reacted with a withdrawal response. The apparatus automatically terminates at a scale reading of $25(=1000 \mathrm{~g})$.

The hot plate test $/ 31 /$ is a more integrated response to a contact thermal pain stimulus. The hot plate response was determined by placing the rats on a $55^{\circ} \mathrm{C}$ copper plate enclosed in a plexiglass cylinder. The interval between placement on the hot plate and the response of licking the hind paws is defined as the 'hot plate latency'. In the absence of a response, the animals were removed after 40 seconds and assigned a hot plate latency of 40 . In studies where multiple repeated testing is required (e.g. the explant study described below), the hot plate test cannot be used, due to interference by learning, which results in jumping immediately after placement in the plexiglass cylinder.

\section{Biochemical analysis}

A spinal superfusion technique $/ 15,16 /$ was used to measure the levels of catecholamines and opioid peptides released into the cerebrospinal fluid (CSF) of animals with various amounts of adrenal medullary or control transplants. To measure release of these substances into spinal cord superfusates, animals were anesthetized with urethane $(1200 \mathrm{mg} / \mathrm{kg})$, fitted with a tracheal tube, and placed in a stereotaxic instrument with the head angled downward. An intrathecal catheter made of PE10 tubing was threaded down the intrathecal space of the rats via a small slit in the atlantooccipital membrane. The tip of the catheter lay at the lumbar enlargement, where the transplant had been previously placed. The rostral end of the catheter was connected to the infusion end of a push-pull pump. Saline containing bacitracin (30 $\mu \mathrm{g} / \mathrm{l})$ and bovine serum albumin $(100 \mathrm{mg} / \mathrm{l})$, to inhibit peptidase activity and reduce non-specific binding, respectively, was constantly infused at a rate of $0.1 \mathrm{ml}$ per minute. Outflow was collected via PE50 tubing placed over the opening in the dura. Following a 30-45 minute superfusion period to allow for stabilization of basal release, three $5 \mathrm{~min}$ samples were collected sequentially. After collection of the third sample, nicotine $(0.1 \mathrm{mg} / \mathrm{kg}$, s.c.) or saline was injected, and an additional 5 min sample was collected. The superfusate samples were divided into two groups for enkephalin and catecholamine assays, respectively. The samples for catecholamine assays were collected into tubes containing antioxidants $(2.5 \mathrm{mg} / \mathrm{ml} \mathrm{L-cysteine,} 0.5$ $\mathrm{mg} / \mathrm{ml}$ sodium metabisulfite, and $4.0 \mathrm{mg} / \mathrm{ml}$ EDTA). All samples were frozen and lyophilized until assayed.

Met-enkephalin release was assessed using standard radioimmunoassay (RIA) techniques with Met-enkephalin antiserum (Incstar, final dilution 1:6000). This antibody has been shown to crossreact $2.8 \%$ with Leu-enkephalin, $0.1 \%$ with $\alpha$ endorphin, and $<0.002 \%$ with substance $P, \beta$ endorphin, dynorphin 1-13, and $\alpha$-neo-endorphin. Prior to assay, samples were reconstituted in $0.2 \mathrm{~N}$ $\mathrm{HCl}$ and extracted on Sep-Pak preparatory cartridges (Waters) to remove salts. Peptides were eluted from the columns with $60 \%$ acetonitrile in $0.1 \%$ trifluoroacetic acid. Serially diluted Metenkephalin standards (Bachem) were used for generation of the standard curve. The reaction was stopped using IgGsorb (Enzyme Center; diluted 
1:40) and the bound fraction was pelleted for counting. The sensitivity limit for this assay was determined to be $0.5 \mathrm{pg}$ of Met-enkephalin. Sample concentrations were corrected for recovery of authentic Met-enkephalin which was $95-99 \%$.

Catecholamine samples were resuspended in 0.4 $\mathrm{N} \mathrm{HClO}_{4}$, and extracted by alumina adsorption. Standards containing authentic norepinephrine (NE), epinephrine (EPI), and dopamine (DA) were processed along with the CSF samples. Recoveries for all three catecholamines were $70-90 \%$. Catecholamines were quantified using reverse-phase HPLC with electrochemical detection. The HPLC mobile phase was $0.07 \mathrm{M} \mathrm{Na}_{2} \mathrm{HPO}_{4}, 0.2 \mathrm{mM}$ octyl sodium sulfate, $0.1 \mathrm{mM}$ EDTA, $8 \%$ methanol, $\mathrm{pH}$ 4.8, and the flow rate over a Waters Resolve C18 column was set at $1.0 \mathrm{ml} / \mathrm{min}$. Catecholamine concentrations in the samples were calculated from relative peak areas corrected for recovery using a Waters Baseline 810 system. The lower detection limits for the assay were 5-10 pg.

\section{Morphologic analysis}

At the termination of the studies, transplant viability was analyzed morphologically using immunocytochemical techniques. The rats were deeply anesthetized with pentobarbital $(50 \mathrm{mg} / \mathrm{kg}$, i.p.), and perfused via the aorta with saline followed by $4 \%$ paraformaldehyde in $0.1 \mathrm{M}$ phosphate buffer. Parts of the spinal cord containing the transplants were dissected and placed in $20 \%$ sucrose in $0.1 \mathrm{M}$ phosphate buffer overnight at $4^{\circ} \mathrm{C}$ for cryoprotection. Fifteen micron sections were cut on a cryostat (Hacker-Bright) and processed for tyrosine hydroxylase (TH) immunoreactivity (Incstar, diluted 1:500) with a rhodamine-linked secondary antibody (Cappel, diluted 1:100). Preimmune serum was used on control sections. The sections were coverslipped in Fluoromount, and observed in a Zeiss Axiophot fluorescence microscope. In some cases, to assess potential host spinal compression, particularly following the implantation of large volumes of tissue, spinal cord tissue was embedded in Epon, and semi-thin sections were stained with toluidine blue.

\section{Experimental design}

\section{Minimum and optimal adrenal medullary tissue for pain reduction}

To determine the effective range of adrenal medullary tissue necessary to produce analgesia, animals were implanted with medullary tissue dissected from $1,2,4,6,8$, or 10 adrenal glands. Six animals received each of the doses of adrenal medullary implants. Control animals were implanted with corresponding volumes of striated muscle tissue ( $\mathrm{n}=12$, such that two animals received graft volumes equal to each adrenal medullary transplant group). Pain sensitivity was assessed at 2, 4, 8, and 12 weeks following transplantation. Baseline pain sensitivity and response to nicotine stimulation $(0.1 \mathrm{mg} / \mathrm{kg}$, s.c.) were determined at these time points, since previous findings have indicated that this dose reliably produces analgesia in animals with adrenal medullary but not control transplants $/ 16,18 /$. Following termination of behavioral testing, CSF samples were collected from the animals using spinal superfusion as described above. Both basal release and release following nicotine stimulation $(0.1 \mathrm{mg} / \mathrm{kg}$, s.c.) were analyzed for catecholamines and Met-enkephalin levels.

\section{Adrenal medullary explants}

In order to determine whether graft tissue can be maintained in culture prior to transplantation, animals were implanted with adrenal medullary tissue either immediately (within $30 \mathrm{~min}$ ) following dissection from adrenal cortical tissue, or following a period of $1,3,7,10,14,21$, or 30 days in culture ( $n=9-10$ animals per group). Animals received the adrenal medullary tissue derived from two adrenal glands, and control animals received equal volumes of striated muscle maintained in parallel cultures. Baseline nociceptive responses and responses to nicotine stimulation $(0.1 \mathrm{mg} / \mathrm{kg}$, s.c.) were assessed $2,4,8$, and 12 weeks following tissue implantation into the spinal cord. At the end of behavioral testing procedures, animals were perfused for immunocytochemical analysis of the grafts as described above. 


\section{Statistical analysis}

Statistical comparisons for overall significance between treatment groups at each time point were done using analysis of variance (ANOVA). Multiple post-hoc analysis for comparisons between individual treatment groups was done using the Neuman-Keuls test /24/.

\section{RESULTS}

\section{Minimum and optimal adrenal medullary tissue for transplantation}

In order to determine whether increasing the amount of adrenal medullary tissue transplanted to the spinal subarachnoid space can produce increased antinociceptive potency, transplant tissue amounts ranged from adrenal medullary tissue derived from 1-10 adrenal glands. Since baseline nociceptive responses were not altered in any of the transplant groups, these were omitted for clarity of presentation. These baseline nociceptive responses as assessed by the three analgesiometric tests were comparable to those obtained in other studies in intact, non-transplanted animals (e.g. see /7/), indicating that the surgical implantation procedures, regardless of volume transplanted, produced no significant alterations in baseline nociceptive thresholds. In addition, no obvious signs of motor impairment were observed in any of the animals in response to transplantation.

Results of this study are shown in Figure 2. Animals receiving control striated muscle transplants were grouped together, since there were no significant changes in pain responsiveness in these animals following nicotine stimulation $(P>$ 0.05 ). In contrast, in animals receiving any amount of adrenal medullary tissue, even from only one adrenal gland, significant antinociception following nicotine was observed as assessed by the tail flick test (Fig. 2A; $P<0.05$ ). Statistically significant antinociception was not produced by one adrenal medullary transplant when assessed by the paw pinch or hot plate tests (Fig. 2B and C; $\mathrm{P}>0.05$ ). However, all other graft amounts, ranging from 210 adrenal medullae, produced significant
NUMBER OF ADRENAL MEDULLAE
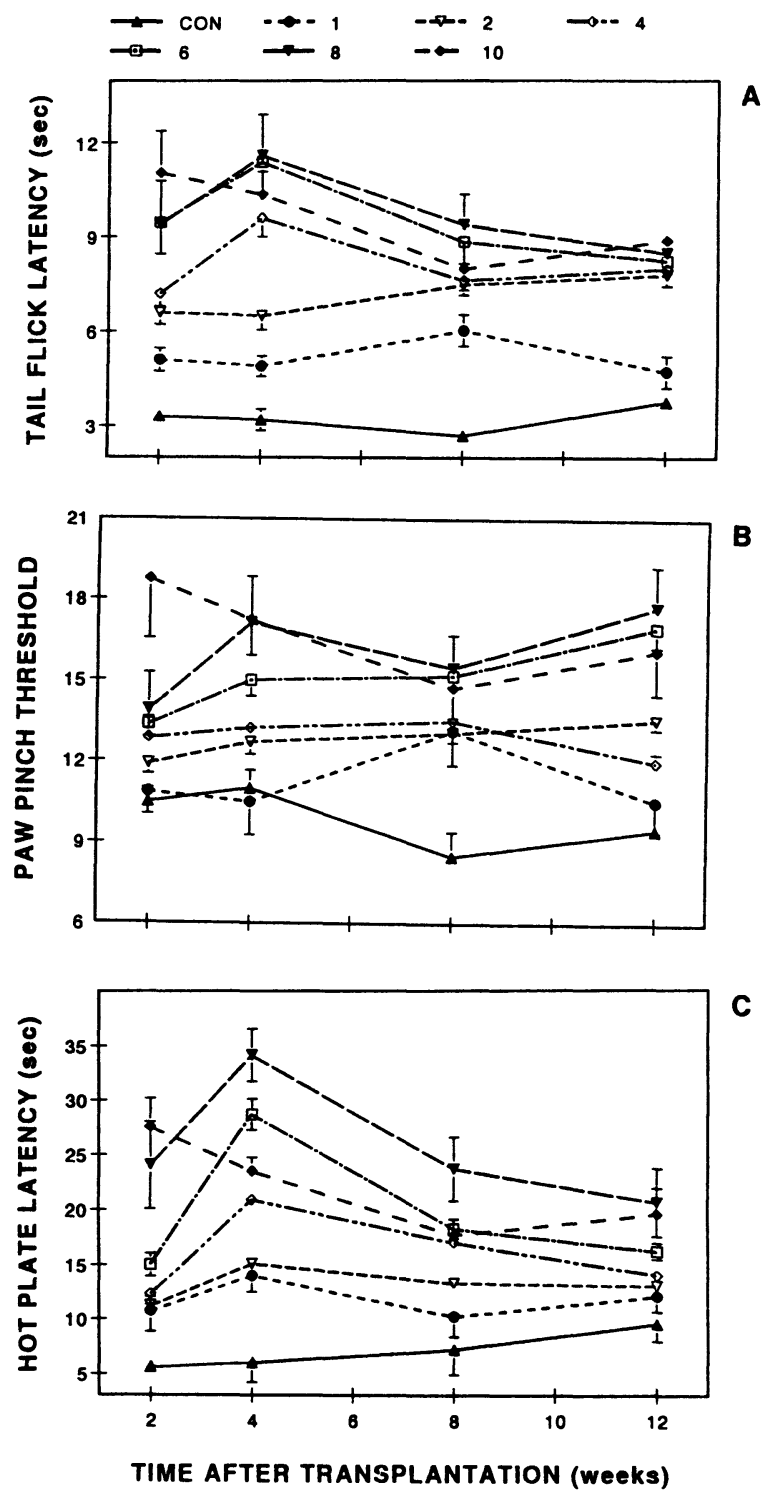

Fig. 2: Effect of transplants of 1 to 10 adrenal medullae or control tissue in the spinal cord subarachnoid space of rats $2 \mathrm{~min}$ following nicotine injection $(0.1 \mathrm{mg} / \mathrm{kg}$, s.c.). The ordinate is the threshold for response to noxious stimuli as assessed by the tail flick test (A), paw pinch test (B), and hot plate test (C). Each point represents the mean \pm S.E.M. The abscissa is months after transplantation. Overall $n=48$ animals; overall $F$ values for each time point $(\mathrm{df}=6,47 ; \mathrm{P}<0.01)=39.08,43.44$, $63.40,75.42$ (tail flick; 2, 4, 8, and 12 weeks, respectively); 44.99, 52.55, 53.02, 22.58 (paw pinch; $2,4,8$, and 12 weeks, respectively); 14.72, 26.78. 14.84, 30.85 (hot plate; 2, 4, 8, and 12 weeks, respectively). 
antinociception with these tests $(\mathrm{P}<0.05$ compared to control transplanted animals). In addition, in general there appeared to be a trend towards increasing antinociceptive potency with increasing amounts of adrenal medullary tissue transplanted, particularly at the earlier phases post-transplantation (2-4 weeks). For example, significant improvements in tail flick antinociceptive potency were obtained when two or more glands were used compared to one transplanted adrenal medulla $(\mathrm{P}<$ 0.05 ). In addition, increases to 6,8 , or 10 glands produce greater antinociception $(P<0.05)$. However, these differences were most pronounced in the early post-transplantation period, and by 12 weeks post-transplantation, while slight improvements in antinociceptive potencies were still seen in animals with larger graft amounts, these were not statistically significant $(P>0.05$ between transplant groups ranging from 2-10 glands) using the tail flick test. Similar trends were obtained using the hot plate and paw pinch tests, which revealed an initial improved antinociceptive potency with increasing transplant amounts. As with the tail flick test, this tended towards equal potencies by 12 weeks posttransplantation, with a slight, but statistically insignificant increase in antinociception in animals with larger graft amounts (P > 0.05 between all adrenal medullary transplant groups).

Figure 3 shows the results of direct measurements of catecholamines and Met-enkephalin from different amounts of adrenal medullary tissue in the spinal CSF using the superfusion technique. The mean basal release of NE in the spinal CSF was significantly increased in animals with adrenal medullary transplants compared to animals with control transplants (Fig. 3A; P < 0.05). Basal NE levels were increased greatly by the transplantation of two adrenal medullae compared to one gland $(P$ $<0.05$ ). While increasing amounts of adrenal medullary tissue further increased basal CSF NE levels, only 10 adrenal glands reached statistically different levels. Basal levels of EPI were also increased in adrenal medullary transplanted animals compared to control transplanted animals $(\mathrm{P}<0.05$ for all adrenal medullary transplanted groups), with further increases reaching statistical significance for only the group receiving 10 adrenal medullae.
Similarly basal DA levels were slightly, but significantly, increased in animals receiving 2-10 adrenal medullae $(P<0.05)$. Fig. 3B shows catecholamine levels in spinal CSF samples following systemic nicotine injection. Nicotine injection had no effect on the CSF levels of NE, EPI, or DA in control transplanted animals $(\mathrm{P}>$ 0.05 compared to basal levels). In contrast, $\mathrm{NE}$ and EPI levels were increased by nicotine in all animals with adrenal medullary transplants. In particular, $\mathrm{NE}$ levels were consistently increased four- or fivefold in animals with 2-10 transplanted adrenal medullae. Nicotine-stimulated DA was also apparent, but only in animals with larger amounts of adrenal medullary tissue transplanted (8-10 glands). Stimulated release of $\mathrm{NE}$ in adrenal medullary transplanted animals was increased in anirnals receiving four compared to two adrenal medullae ( $P$ $<0.05)$, but further increases were not apparent $(P$ $>0.05$ ).

Met-enkephalin release in spinal superfusates is shown in Fig. 3C. Mean basal levels of Metenkephalin release were higher in animals with transplants of 4 to 10 adrenal medullae than those of control animals or with transplants of one to two adrenal medullae $(P<0.05)$. Nicotine produced significant increases in Met-enkephalin release from basal levels in animals with transplants of two to ten adrenal medullae $(P<0.01)$, but not in animals with transplants of either one adrenal medulla or control muscle $(P>0.05)$. An intermediate amount of adrenal medullary tissue (6 medullae) appeared to release the highest levels of Met-enkephalin following nicotine, with decrements when more tissue was added, but the differences between 2 and 10 adrenal medullae were not statistically significant $(\mathrm{P}>0.05)$.

The appearance of host spinal cord from an animal receiving 10 adrenal medullae is shown in Figure 4. Fig. $4 \mathrm{~A}$ is a low magnification showing a portion of the transplanted adrenal medullary tissue lying at the dorsal surface of the host spinal cord. The transplanted tissue appears to fill the available subarachnoid space beneath the dura mater, and surrounds the host dorsal spinal vein. There is no apparent damage or compression to host spinal cord parenchyma. At higher magnification in Fig. 4B, a 


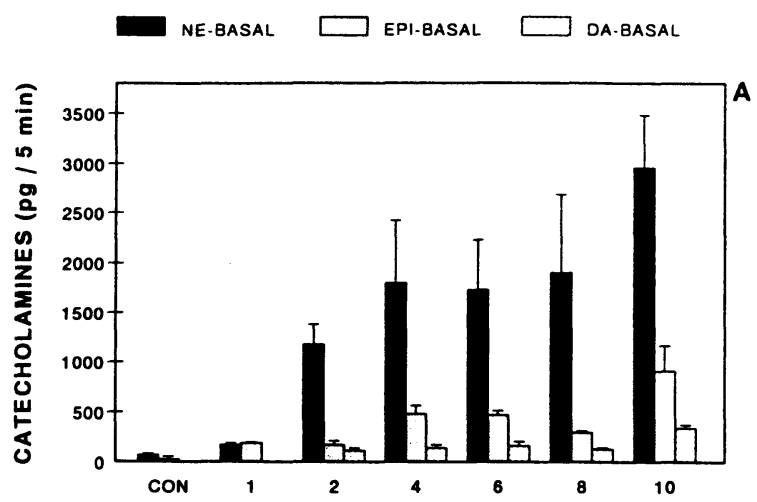

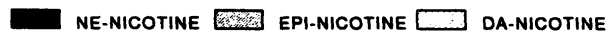

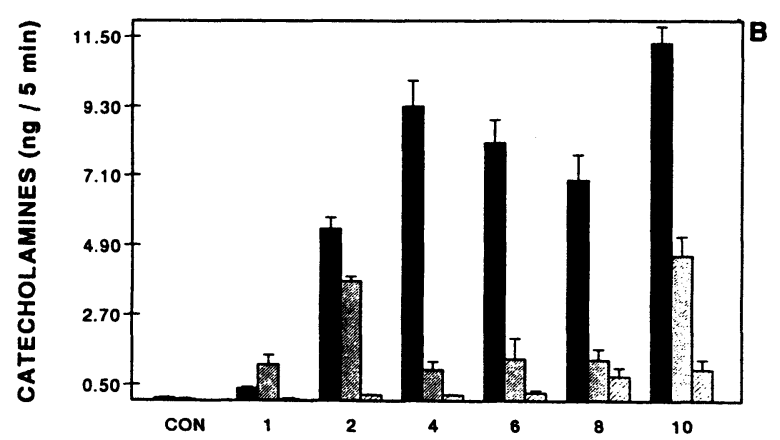

ENK-BASAL ENK-NICOTINE

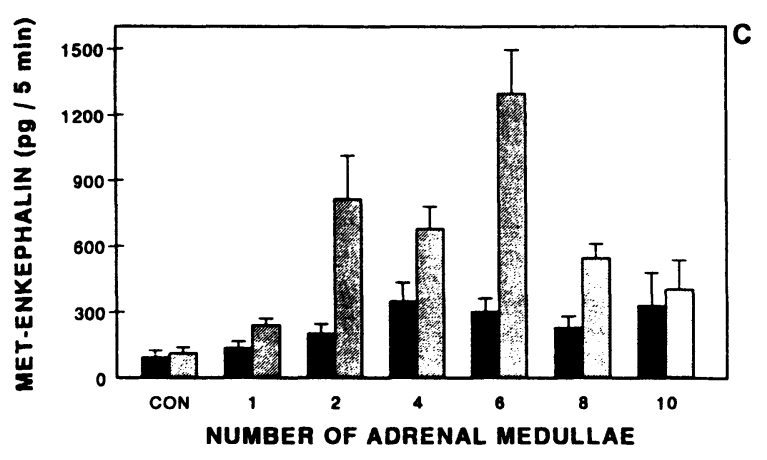

cluster of chromaffin cells can be seen. These transplanted cells retain their in situ cuboidal morphology, and are well vascularized. The remainder of the transplanted tissue contains elements of connective tissue including fibroblasts and collagen.
Fig. 3: Release of catecholamines and Met-enkephalin in spinal superfusates of animals with adrenal medullary or control transplants. A. Basal catecholamine release in the spinal CSF of animals with transplants of 1 to 10 adrenal medullae or control striated muscle in the spinal cord subarachnoid space 3 months following surgery. Bars represent the mean \pm S.E.M. levels of norepinephrine, epinephrine, and dopamine per 5 min sample collection interval. B. Nicotine stimulated release of catecholamines into spinal cord superfusates in animals with transplants of 1 to 10 adrenal medullae or control tissue in the spinal cord subarachnoid space. Bars represent the mean \pm S.E.M. levels of norepinephrine, epinephrine, and dopamine in the $5 \mathrm{~min}$ interval following nicotine injection $(0.1 \mathrm{mg} / \mathrm{kg}$, s.c.). C. Basal and nicotine-stimulated release of Met-enkephalin into spinal cord superfusates in animals with transplants of 1 to 10 adrenal medullae or control tissue. Spinal CSF samples were collected before and $5 \mathrm{~min}$ after nicotine injection $(0.1 \mathrm{mg} / \mathrm{kg}$, s.c.). NE-BASAL = basal norepinephrine release; EPI-BASAL = basal epinephrine release; DA-BASAL = basal dopamine release; NE-NICOTINE = nicotinestimulated norepinephrine release; EPINICOTINE = nicotine-stimulated epinephrine release; DA-NICOTINE = nicotine-stimulated dopamine release; ENK-BASAL = basal Metenkephalin release; ENK-NICOTINE = nicotinestimulated Met-enkephalin release; $\mathrm{CON}=$ control (striated muscle) transplants. Overall $n=48$ animals; overall $\mathrm{F}$ values for each release group $(\mathrm{df}=6,47 ; \mathrm{P}<0.01)=17.87$ (NE-BASAL); 19.87 (NE-NICOTINE); 33.46 (EPI-BASAL); 22.07 (EPI-NICOTINE); 22.39 (DA-BASAL); 8.09 (DA-NICOTINE); 5.22 (ENK-BASAL); 29.01 (ENK-NICOTINE).

\section{Tissue culture maintenance of adrenal medullary explants}

The purpose of this series of studies was to determine whether adrenal medullary tissue can be maintained in explant culture over a period of time 

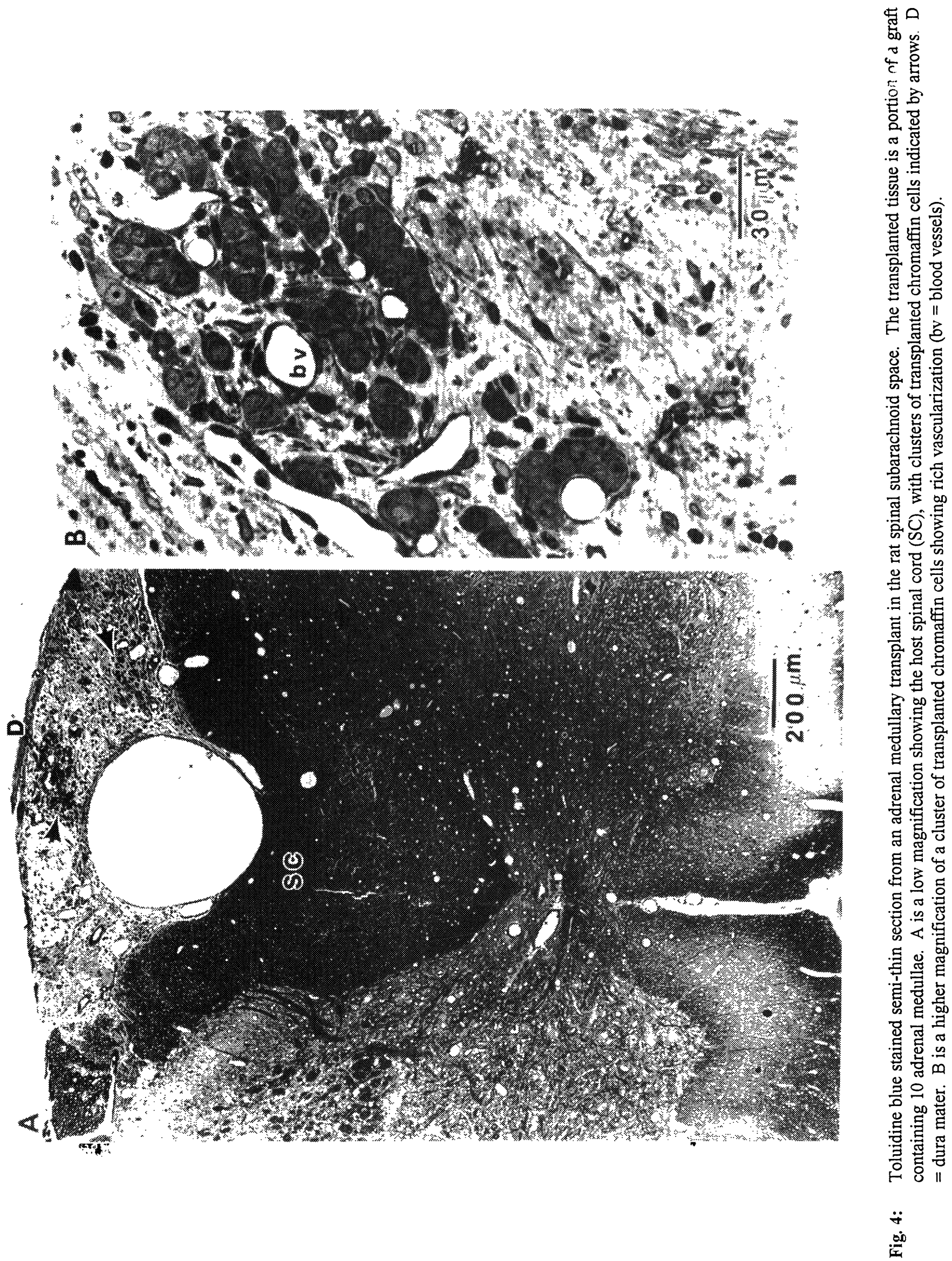
prior to transplantation without significant decrement in viability or pain-reducing capabilities. Figures 5 and 6 show antinociceptive responses following transplantation of adrenal medullary explants as assessed by the tail flick (Fig. 5) and

\section{WKS AFTER TRANSPLANT}

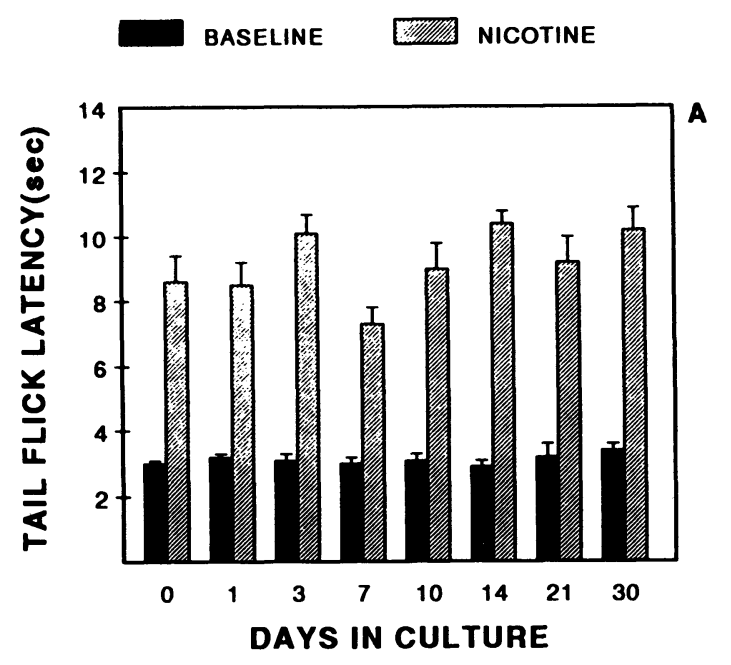

4 WKS AFTER TRANSPLANT

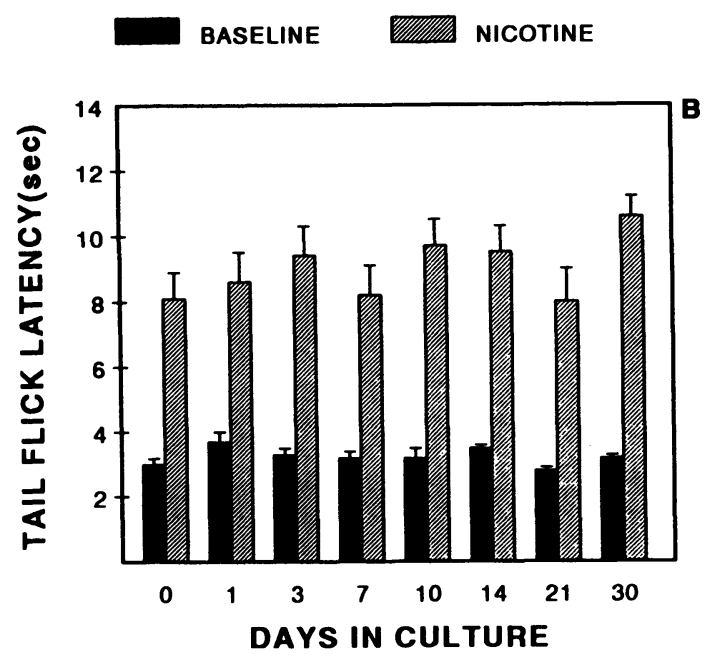

paw pinch (Fig. 6) tests. As assessed by the tail flick test, nicotinic stimulation produced significant antinociception in animals with either direct adrenal medullary transplantation, or transplantation of adrenal medullary explants maintained in culture for

\section{WKS AFTER TRANSPLANT}

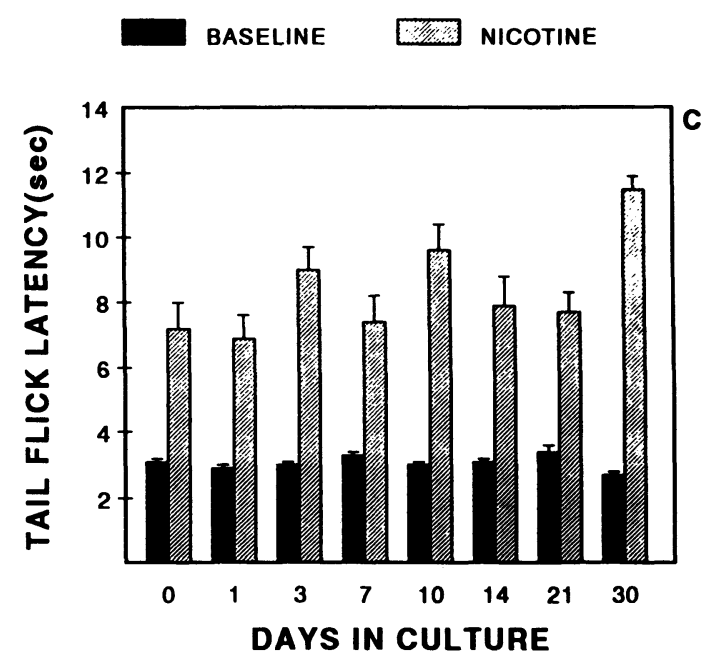

12 WKS AFTER TRANSPLANT

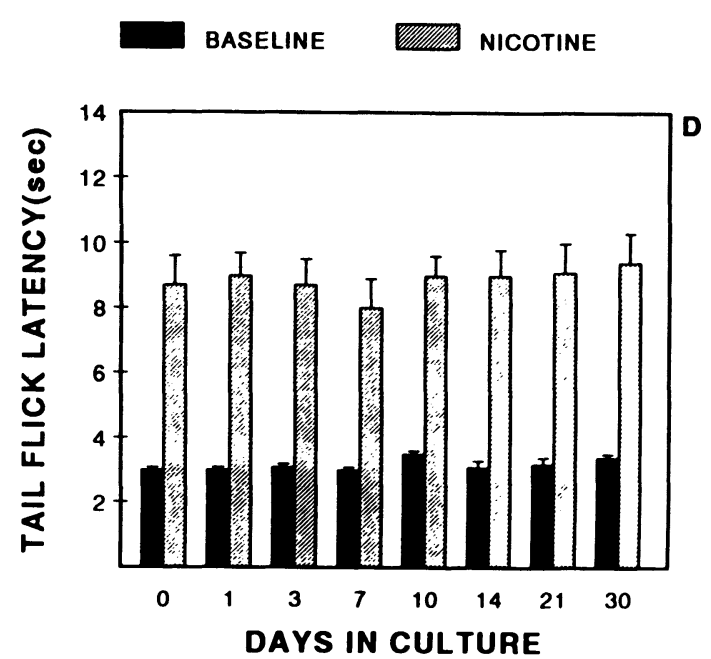

Fig. 5: Effects of explanted adrenal medullary tissue in the spinal cord subarachnoid space of rats on pain sensitivity assessed by the tail flick test. The abscissa shows the number of days explants were maintained in culture prior to transplantation. The ordinate is the threshold for response to the noxious stimulus as determined by the test. The solid bar in each pair is the baseline pain threshold. The cross-hatched bar in each pair is response 2 min following nicotine injection $(0.1 \mathrm{mg} / \mathrm{kg}$, s.c.). The equivalent of medullary tissue dissected from two adrenal glands was used in all animals. A, B, C, D: 2, 4, 8, and 12 weeks after transplantation, respectively. Overall $\mathrm{n}=$ 78 animals; overall $\mathrm{F}$ values following nicotine for each time point $(\mathrm{df}=7,77)=1.71$ ( 2 weeks); 1.96 (4 weeks); 2.23 (8 weeks); 2.10 (12 weeks). $P>0.05$ for all groups, indicating that maintenance in tissue culture does not result in significant decrement in antinociceptive potency. 
2 WKS AFTER TRANSPLANT

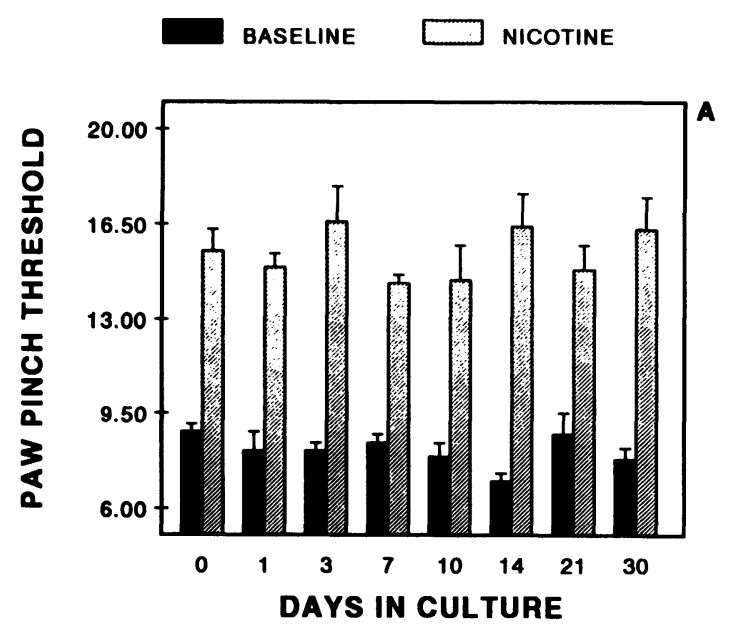

4 WKS AFTER TRANSPLANT

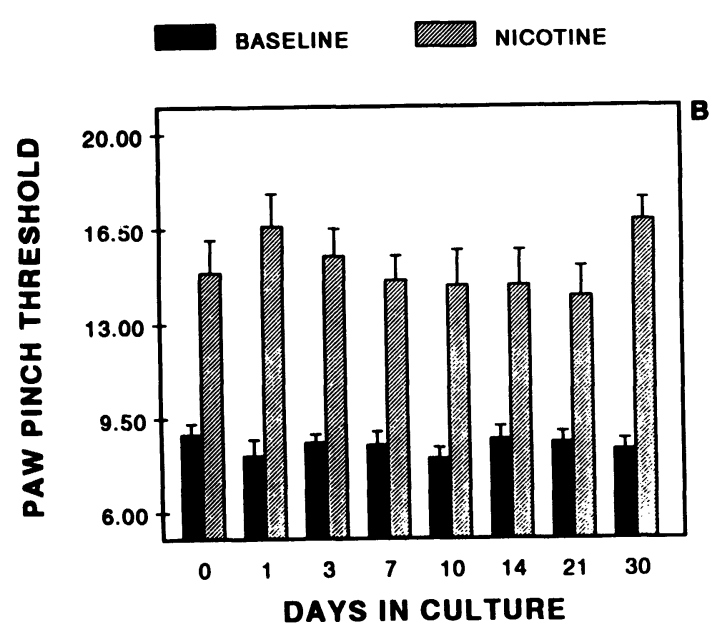

8 WKS AFTER TRANSPLANT

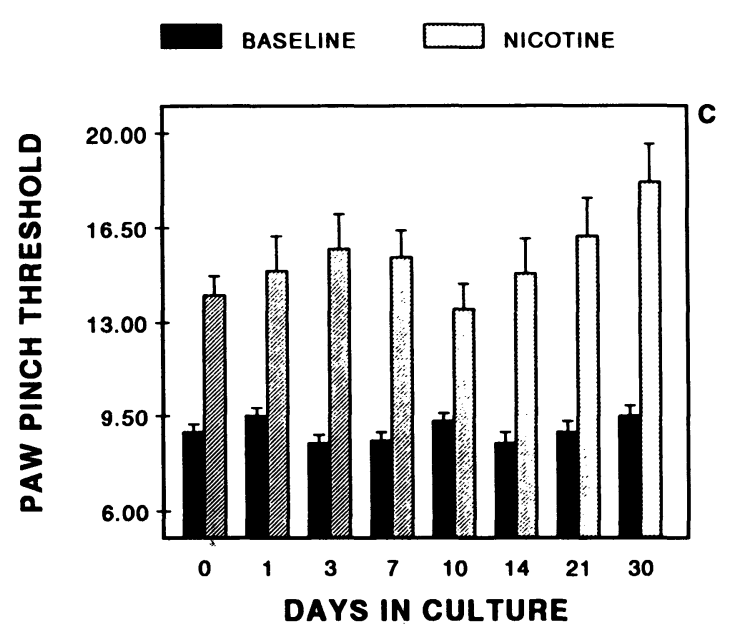

12 WKS AFTER TRANSPLANT

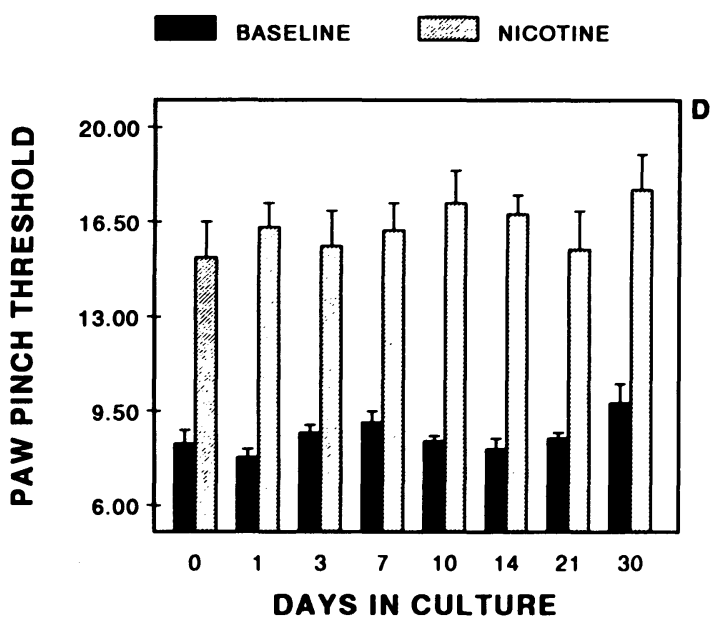

Fig. 6: Effects of explanted adrenal medullary tissue in the spinal cord subarachnoid space of rats on pain sensitivity assessed by the paw pinch test. The abscissa shows the number of days explants were maintained in culture prior to transplantation. The ordinate is the threshold for response to the noxious stimulus as determined by the test. The solid bar in each pair is the baseline pain threshold. The second bar in each pair is the response 2 min following nicotine injection $(0.1 \mathrm{mg} / \mathrm{kg}, \mathrm{s.c}$.$) . The equivalent of medullary tissue dissected from two adrenal$ glands was used in all animals. A, B, C, D: 2, 4, 8, and 12 weeks after transplantation, respectively. Overall $n=$ 78 animals; overall $\mathrm{F}$ values following nicotine for each time point $(\mathrm{df}=7,77)=1.04$ ( 2 weeks); 0.74 (4 weeks); 0.58 (8 weeks); 0.40 (12 weeks). P > 0.05 for all groups, indicating that maintenance in tissue culture does not result in significant decrement in antinociceptive potency.

various time periods ranging from $1-30$ days $(\mathrm{P}<$ 0.05). Similar to earlier findings, this dose of nicotine produced no effect in animals with control striated muscle transplants ( $P>0.05$, not shown). The antinociceptive potency of the explants was maintained without significant decrement from 2 to
4, 8, and 12 weeks post-transplantation (Fig. 5 AD; $\mathrm{P}>0.05$ between times after transplantation). The results following maintenance in explant culture revealed that there was no reduction in the potency of adrenal medullary transplants whether they were implanted immediately following dissection or kept 
in tissue culture for up to 30 days prior to transplantation $(\mathrm{P}>0.05$ between transplant groups at all time points). Findings using the paw pinch test were virtually identical, showing no significant decrements in antinociceptive potency of the transplants over time, whether the medullary tissue was transplanted immediately, or after 1-30 days in culture (Fig. 6 A-D).

Following termination of behavioral testing, animals receiving adrenal medullary transplants or explants were perfused, and their spinal cords processed for tyrosine hydroxylase (TH) immunocytochemistry to assess chromaffin cell viability (Fig. 7). Twelve weeks after transplantation, adrenal medullary tissue implanted immediately after dissection contained numerous TH-positive cells, as described in previous studies (Fig. 7, Day 0). Transplants of tissues maintained in culture for 1-3 days appeared to contain fewer, but still numerous TH positive cells, possibly due to transplantation in the early stages following dissections. In contrast, transplants of tissues maintained in culture for $7,10,14,21$ and 30 days contained numerous TH positive cells, with the greatest density between 7 and 21 days in culture. These TH positive cells did not appear to sprout processes and retained their in situ cuboidal morphology. In addition, these grafts typically remained in the spinal cord subarachnoid space and did not integrate noticeably with the surrounding host CNS parenchyma.

\section{DISCUSSION}

Previous findings in our laboratory have demonstrated that adrenal medullary allografts in the rat spinal subarachnoid space can reduce pain sensitivity, most likely by providing a sustained and renewable source of pain-reducing neuroactive substances such as opioid peptides and catecholamines $/ 10,15,16,18,20 /$. The success of these rodent studies has led to the initiation of limited clinical trials in human cancer patients with promising results $/ 19 /$. However, before large-scale clinical trials should be undertaken, especially in light of the variable and often disappointing outcomes in the clinical Parkinson's disease transplantation programs (see /6,7/), there are many unknowns that could be readily addressed in the laboratory. The goal of this work was to address some of these issues and so lead to more consistent and effective outcomes in future clinical trials.

One aspect of these studies was to determine whether an optimal amount of adrenal medullary tissue exists in order to produce reliable pain reduction. Using behavioral antinociceptive assays, results indicated that, while tissue from one adrenal medulla can produce some antinociception, this can be improved significantly by the transplantation of tissue from two or more adrenal medullae. The further inclusion of greater amounts of adrenal medullary tissue appears to augment antinociceptive potency in a correlative fashion, but these differences are apparent primarily in the early posttransplantation phases. At later periods, the beneficial effects of larger amounts of adrenal medullary tissue in the transplants, while not completely eliminated, diminish to a large extent. Thus, an intermediate amount of adrenal medullary tissue (e.g. from 2 to 6 glands) seems to be sufficient for maximally attainable antinociception using this technique.

One possible explanation for the finding that increasing graft tissue amounts does not result in sustained improvements in antinociceptive potency is that the high levels of exposure to analgesic agents released by the transplants results in the development of host tolerance. In particular, tolerance to opioids, resulting in diminished antinociceptive potency is a well-documented result of repeated or continual administration $/ 1,14,25$, $33,34 \%$ Previous findings in our laboratory have suggested that there is little tolerance development in animals with transplants from two adrenal glands 128/. However, exposure of the host spinal cord to increased levels of these agents by greater amounts of transplanted adrenal medullary tissue could result in tolerance development. Similarly, exposure to high levels of opioid peptides by transfected AtT-20 cells, which produce both $\beta$-endorphin and proenkephalin products, produces rapid tolerance to opioids after transplantation in the spinal subarachnoid space $/ 32 /$. These results suggest the interesting possibility that an optimal level of adrenal medullary tissue for transplantation does not 


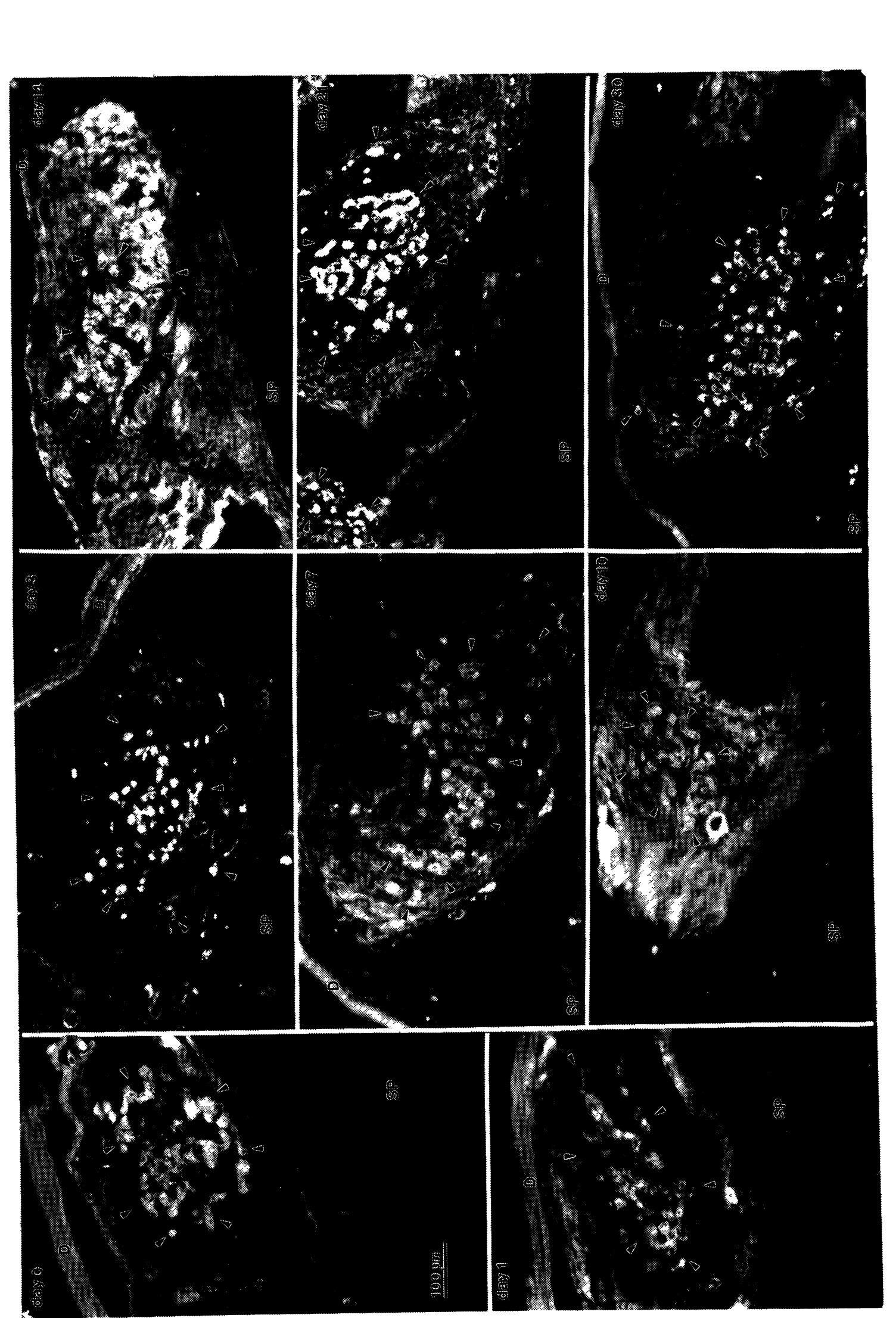

놇 뭉

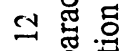

至寻焉

행 营

큽

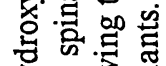

宓客

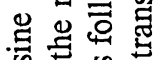

인.苍导

(1)

눙웛.

प्ष్ల

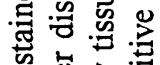

论壳密

澏豆

응 坖㟔

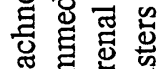

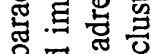

急焉売

뭉 善出:

ส 콘

䓛运

品矛응 흥

. 完密

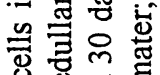

몀염

续焉

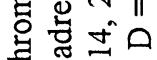

긍

켱응

产向可

गु कि

递它

주웡

눈데

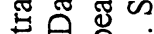

岁过雚

क्षे की

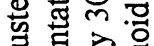

ช。

出总

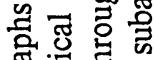

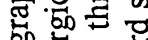

능

象哭焉

욤

모음

$\ddot{r}$ 
necessarily require large amounts of donor material, which may, in fact, be detrimental due to host tolerance development. Rather, subeffective levels of synergistic pain-reducing neuroactive substances provided by smaller amounts of adrenal medullary tissue may be optimal. In support for this, the synergistic antinociception provided by the coactivation of spinal opioid and $\alpha$-adrenergic receptors is well documented and, using subeffective levels of agents acting at both, may also result in reduced tolerance development $14,22,29,36 /$. Thus, the combination of neuroactive substances produced by adrenal medullary transplants may optimally produce co-activation of opioid and $\alpha$-adrenergic receptors with subeffective levels of both classes of agents.

One possible contradiction in the explanation that tolerance development accounts for the failure of increasing amounts of adrenal medullary tissue to produce increased analgesia is that antinociceptive effects are not completely eliminated in the presence of high levels of graft tissue; rather these levels produce antinociception similar to that of smaller amounts of adrenal medullary transplants. In addition, neurochemical assays suggest that markedly increased levels of catecholamines and opioid peptides are not produced by large amounts of adrenal medullary tissue transplants. Thus, tolerance development may be a factor in the inability to increase antinociceptive potency, but cannot completely account for the observed findings. Another possibility is that there is poor survival of adrenal medullary tissue in the spinal subarachnoid space beyond an optimal level. Alternatively, increased exposure of grafted cells to their released products could result in feedback inhibitory mechanisms resulting in lowered output of neuroactive substances. Results from the superfusion studies tend to support this to some extent, revealing substantially increased catecholamine and Met-enkephalin release when transplant tissue is increased from one to two glands, but only slight increases beyond that. This is contrary to expected linearly-related increases in neuroactive substances provided by increasing numbers of transplanted chromaffin cells. In support for this, continued exposure to both catecholamines and opioid peptides has been shown to reduce basal and nicotine-evoked secretion from adrenal medullary cells in culture $15,9,11,21,26 /$.

Regardless of the mechanisms, results of the first part of these studies indicate that small quantities of adrenal medullary tissue (e.g. from two adrenal glands) are necessary and sufficient to produce optimal CSF levels of pain-reducing neuroactive substances for sustained antinociception. In the second part of the study, the potential for increasing usefulness of donor adrenal medullary tissue by maintaining it in culture until recipient and graft availability can be coordinated, was assessed. Results indicated that there was no decrement in antinociceptive potency when the adrenal medullary tissue was kept in culture for up to 30 days. However, interestingly, immunocytochemical staining of $\mathrm{TH}$ indicated denser distributions of TH positive cells in adrenal medullary transplants maintained in culture for longer periods (particularly 7 to 21 days) than those placed in culture for shorter times. Although not quantified, the density of TH positive cells appeared greater in transplants of these cultured adrenal medullary explants than in those transplanted immediately after dissection. These findings suggest that there may be a recovery period following initial trauma from dissection procedures. Similar findings were reported for human adrenal medullary explants /17/. Thus, to maximize chromaffin cell survival, it may be advisable to maintain adrenal medullary tissue in culture for several days, when it is not feasible to transplant the tissue immediately. Another possible advantage of maintenance in explant culture for a period of time is that is may allow for the migration of passenger leukocytes out of the explanted tissue, reducing the potential immunologic response when transplanted to an allogeneic host. However, in this study, pain thresholds assessed by analgesiometric tests were not different, in spite of maintenance for various periods in culture. Thus, regardless of apparent increased chromaffin cell viability in longer term explants, sufficient numbers of chromaffin cells for pain reduction apparently survive following shorter times in culture.

In conclusion, results from this study suggest that small amounts of donor adrenal medullary tissue may be sufficient for producing long-lasting 
pain reduction when transplanted into the spinal subarachnoid space. Furthermore, attempts to improve antinociceptive potency by markedly increasing adrenal medullary tissue may result in supraoptimal delivery of pain-reducing neuro-active substances, leading to host tolerance development or feedback down-regulation in secretion from transplanted cells. Results from this study also indicate that rat adrenal medullary tissue can survive and be transplanted without decrement in antinociceptive potency following maintenance in explant tissue culture for at least one month. One of the problems with the use of human allografts is the difficulty in coordinating organ donor availability and recipient preparation. Findings of the present study suggest that it may be possible, or even preferable, to harvest and maintain viability of donor adrenal tissue without immediate implantation into the host. In summary, results of this study indicate that some of the critical issues for successful neural transplantation outcomes can be initially addressed in pre-clinical studies.

\section{ACKNOWLEDGEMENTS}

We would like to thank Mr. Aldric Hama for assistance in the preparation of this manuscript, and Ms. Mary Lavallee for expert technical help in performance of the neurochemical assays. This work was supported by NIH grant NS25054.

\section{REFERENCES}

1. Advokat $\mathrm{C}$, Burton $\mathrm{P}$, Tyler CB. Investigation of tolerance to chronic intrathecal morphine infusion in the rat. Physiol Behav 1987; 39: 161-168.

2. Boarder MR, Lockfeld AJ, Barchas JD. Metenkephalin [ $\left.\mathrm{Arg}^{6}, \mathrm{Phe}^{7}\right]$ immunoreactivity in bovine caudate and bovine adrenal medulla. J Neurochem 1982; 39: 149-154.

3. D'Amour RE, Smith DL. A method for determining loss of pain sensation. J Pharmacol Exp Ther 1941; 72: 74-79.

4. Drasner K, Fields HF. Synergy between the antinociceptive effects of intrathecal clonidine and systemic morphine in the rat. Pain 1988; 32: 309-312.
5. Foucart $S$, Nadeau $R$, de Champlain J. The release of catecholamines from the adrenal medulla and its modulation by $\alpha_{2}$-adrenoceptors in the anaesthetized dog. Can J Physiol Pharmacol 1987; 65: 550-557.

6. Freed WF. Neural transplantation: Prospects for clinical use. Cell Transplant 1993; 2: 13-31.

7. Freed WF, Rosenstein JM. Neural transplantation: A report on the IVth International Symposium. J Neur Transplant Plast 1993; 4: 61-96.

8. Garces YI, Rabito SF, Minshall RD, Sagen J. Lack of potent antinociceptive activity by substance $P$ antagonist CP-96,345 in the rat spinal cord. Life Sci 1992; 52: 353-360.

9. Greenberg A, Zinder O. $\alpha$ - and $\beta$-receptor control of catecholamine secretion from isolated adrenal medulla cells. Cell Tiss Res 1982; 226: 655-665.

10. Hama AT, Sagen J. Reduced pain-related behavior by adrenal medullary transplants in rats with experimental painful peripheral neuropathy. Pain 1993; 52: 223231.

11. Kumakura K, Karoum F Guidotti A, Costa E. Modulation of nicotinic receptors by opiate receptor agonists in cultured adrenal chromaffin cells. Nature 1980; 283: 489-492.

12. Liston D, Patey G, Rossier J, Verbanck J-J, Vanderhaeghem J-J. Processing of proenkephalin is tissue specific. Science 1984; 225: 734-737.

13. Livett B, Dean DM, Whelan LG et al. Co-release of enkephalin and catecholamines from cultured adrenal chromaffin cells. Science 1981; 225:734-737.

14. Russell RD, Leslie JB, Su Y-F, Watkins WD, Chang KJ. Continuous intrathecal opioid analgesia: tolerance and cross-tolerance of $m u$ and delta spinal opioid receptors. J Pharmacol Exp Ther 1987; 240: 150-1

15. Sagen J, Kemmler JE. Increased levels of metenkephalin-like immunoreactivity in the spinal cord CSF of rats with adrenal medullary transplants. Brain Res 1989; 502: 1-10.

16. Sagen J, Kemmler JE, Wang H. Adrenal medullary transplants increase spinal cord cerebrospinal fluid catecholamine levels and reduce pain sensitivity. J Neurochem 1991; 56: 623-627.

17. Sagen J, Pappas GD. Increased opioid peptide and catecholamine production in human adrenal medullary explants. Soc Neurosci Abstr 1990; 16: 835.

18. Sagen J, Pappas GD, Perlow MJ. Adrenal medullary tissue transplants in the rat spinal cord reduce pain sensitivity. Brain Res 1986; 384: 189-194.

19. Sagen J, Pappas GD, Winnie AP. Alleviation of pain in cancer patients by adrenal medullary transplants in the spinal subarachnoid space. Cell Transplantation 1993; 2: 259-266.

20. Sagen J, Wang H, Pappas GD. Adrenal medullary implants in rat spinal cord reduce nociception in a chronic pain model. Pain 1990; 42: 69-79.

21. Saiani L, Guidotti A. Opiate receptor-mediated 
inhibition of catecholamine release in primary cultures of bovine adrenal chromaffin cells. J Neurosci 1982; 39: 1669-1676.

22. Sherman SE, Loomis CW, Milne B, Cervenko FW. Intrathecal oxymetazoline produces analgesia via spinal $\alpha$-adrenoceptors and potentiates spinal morphine. Eur J Pharmacol 1988; 148: 371-380.

23. Stern AS, Lewis RV, Kimura S, Rossier J, Stein S, Udenfriend S. Opioid hexapeptides and heptapeptides in adrenal medulla and brain: possible implications on the biosynthesis of enkephalins. Arch Biochem Biophys 1980; 205: 606-613.

24. Tallarida RJ, Murray RB. Manual of Pharmacologic Calculations with Computer Programs. New York: Springer-Verlag 1987; 297.

25. Tseng L-F. Tolerance and cross-tolerance to morphine after chronic spinal D-Ala ${ }^{2}$-D-Leu ${ }^{5}$-enkephalin infusion. Life Sci 1982; 31: 987-992.

26. Wakade AR, Malhotra RK, Wakade TD, Dixon WR. Simultaneous secretion of catecholamines from the adrenal medulla and of $\left[{ }^{3} \mathrm{H}\right]$ norepinephrine from sympathetic nerves from a single test preparation: Different effects of agents on the secretion. Neuroscience 1986; 18: 877-888.

27. Wang $H$, Sagen J. Pain reduction by the transplantation of adrenal medullary explants in the spinal subarachnoid space. Soc Neurosci Abstr 1990; 16: 654.

28. Wang H, Sagen J. Absence of appreciable tolerance and morphine cross-tolerance in rats with adrenal medullary transplants in the spinal cord. Neuropharmacology 1994; in press.
29. Wilcox GL, Carlsson K, Jochim A, Jurna I. Mutual potentiation of antinociceptive effects of morphine and clonidine on motor and sensory responses in rat spinal cord. Brain Res 1987; 405: 84-93.

30. Wilson SP, Chang K-J, Viveros OH. Proportional secretions of opioid peptides and catecholamines from adrenal chromaffin cells in culture. Anesthesiology $1982 ; 54: 451-467$

31. Woolfe $G$, MacDonald $A D$. The evaluation of the analgesic action of pethidine hydrochloride (Demerol). J Pharmacol Exp Ther 1944; 80: 300-307.

32. Wu H, McLoon SC, Wilcox GL. Spinal implants of cells genetically modified to produce enkephalin reduce nociceptive sensitivity in host mice. Soc Neurosci Abstr 1992; 18: 781.

33. Yaksh, TL. Multiple spinal opiate receptor systems in analgesia. In: Kruger L, Liebeskind JC, eds, Advances in Pain Research and Therapy. New York: Raven Press 1984; 6: 197-215

34. Yaksh TL, Howe JR, Harty GJ. Pharmacology of spinal pain modulatory systems. Adv Pain Res Ther 1984; 7: 57-70.

35. Yaksh TL, Kohl RL, Rudy TA. Induction of tolerance and withdrawal in rats receiving morphine in the spinal subarachnoid space. Eur J Pharmacol 1977; 42: 275284.

36. Yaksh TL, Reddy SVR. Studies in the primate on the analgetic effects associated with intrathecal actions of opiates, alpha-adrenergic agonists, and baclofen. Anesthesiology 1981; 54: 451-467. 

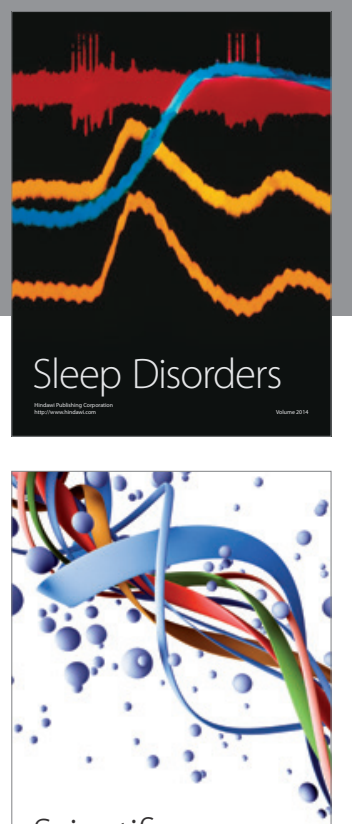

Scientifica
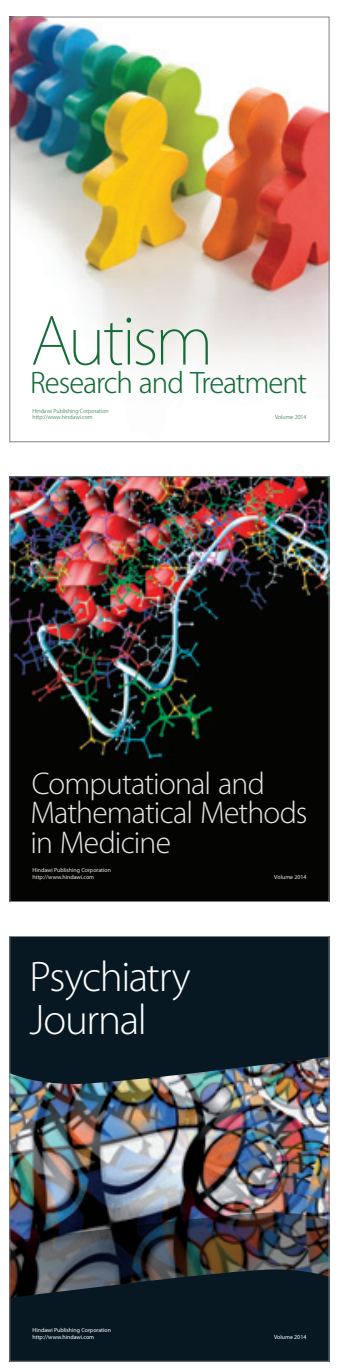
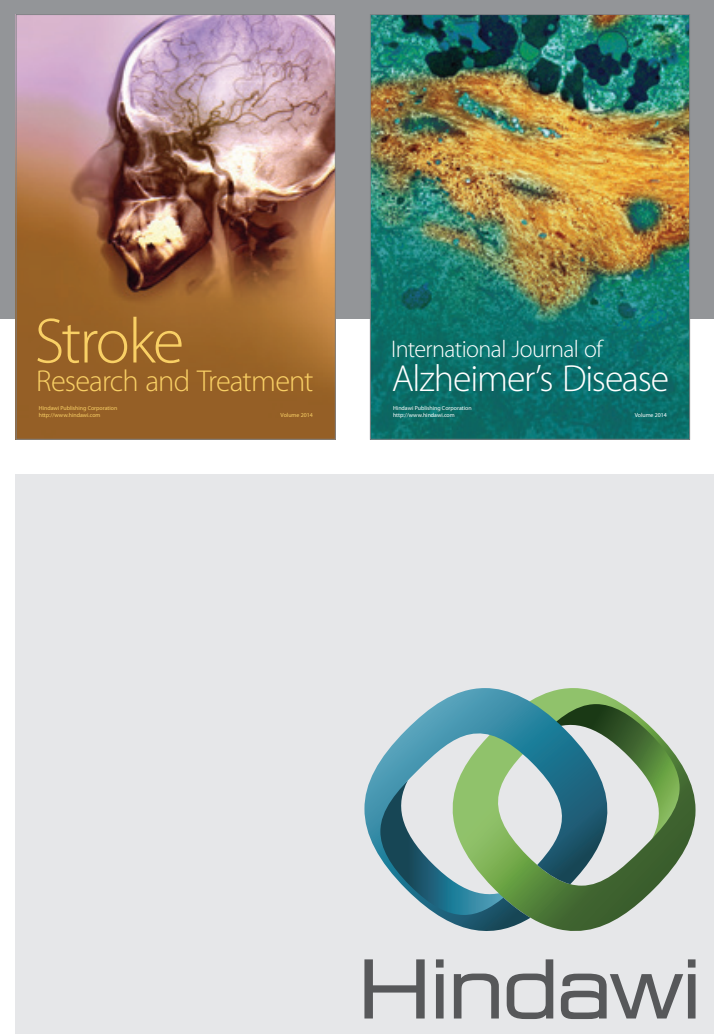

Submit your manuscripts at

http://www.hindawi.com
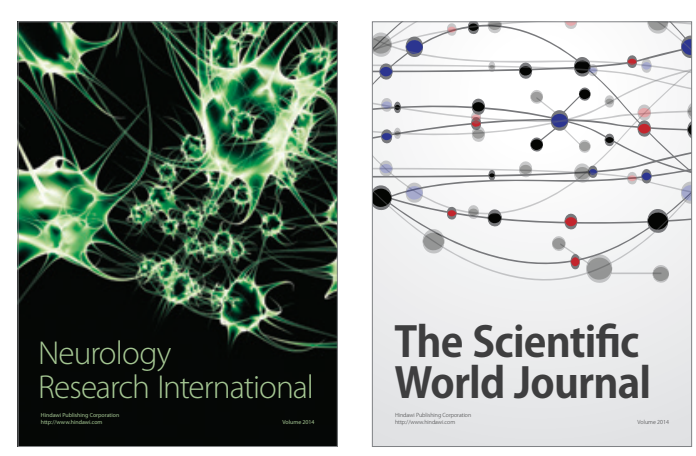

The Scientific World Journal

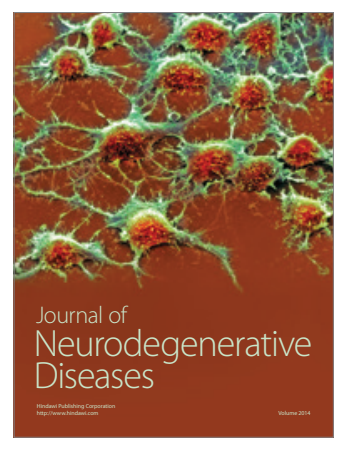

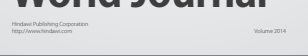

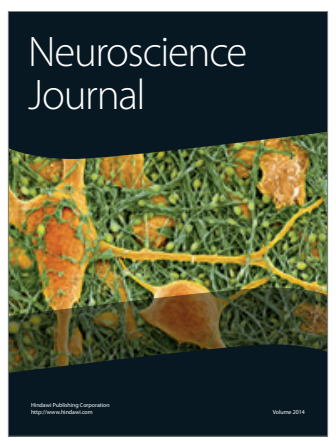

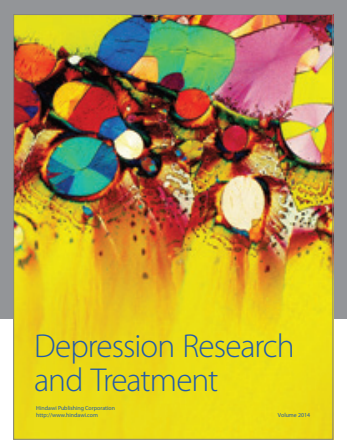
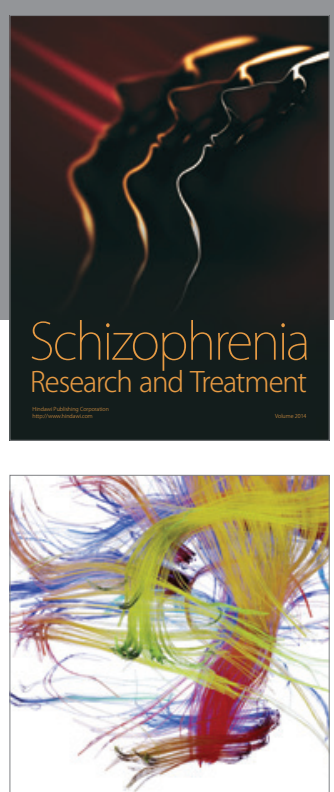

Brain Science

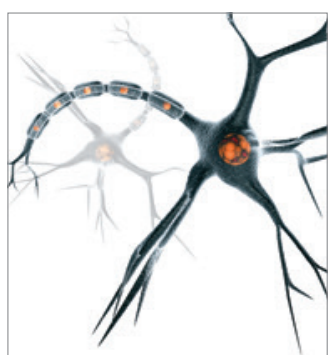

Neural Plasticity
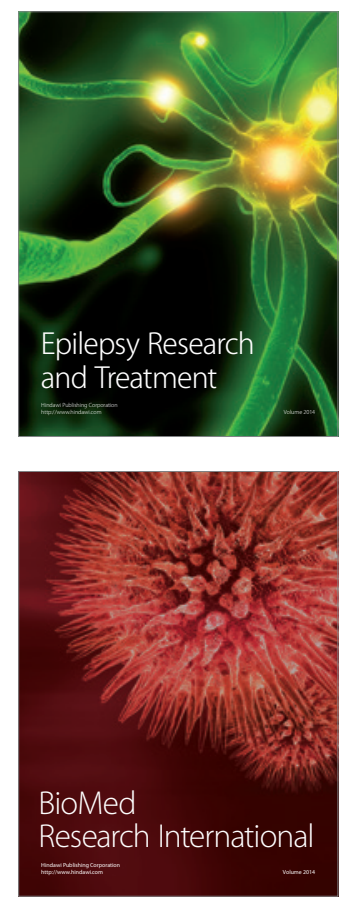

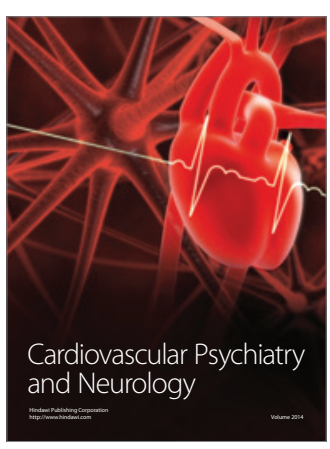

Parkinson's

Disease
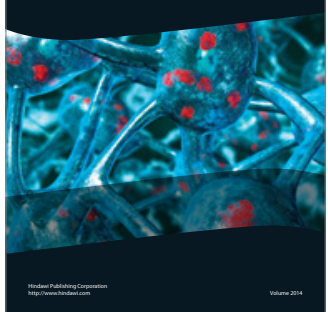